Check for updates

Cite this: RSC Adv., 2017, 7, 19742

Received 13th December 2016

Accepted 19th March 2017

DOI: 10.1039/c6ra28165f

rsc.li/rsc-advances

\section{Shape memory polymers with visible and near- infrared imaging modalities: synthesis, characterization and in vitro analysis $\uparrow$}

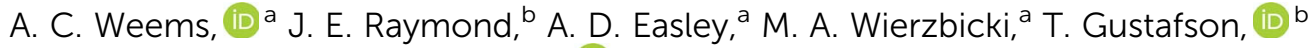 \\ M. B. B. Monroe ${ }^{a}$ and D. J. Maitland (D) *a
}

Shape memory polymers (SMPs) are promising for non-invasive medical devices and tissue scaffolds, but are limited by a lack of visibility under clinical imaging. Fluorescent dyes are an alternative to radiocontrast agents in medical applications, they can be utilized in chemical sensors and monitors and may be anti-microbial agents. Thus, a fluorescent SMP could be a highly valuable biomaterial system. Here, we show that four fluorescent dyes (phloxine B (PhB), eosin $Y$ (Eos), indocyanine green (IcG), and calcein (Cal)) can be crosslinked into the polymer backbone to enhance material optical properties without alteration of shape memory and thermomechanical properties. Examinations of the emission wavelengths of the materials compared with the dye solutions showed a slight red shift in the peak emissions, indicative of crosslinking of the material. Quantitative analysis revealed that $\mathrm{PhB}$ enabled visibility through $1 \mathrm{~cm}$ of blood and through soft tissue. We also demonstrate the utility of these methods in combination with radio-opaque microparticle additives and the use of laserinduced shape recovery to allow for rapid shape recovery below the glass transition temperature. The crosslinking of fluorescent dyes into the SMP enables tuning of physical properties and shape memory and independently of the fluorescence functionality. This fluorescent SMP biomaterial system allows for use of multiple imaging modalities with potential application in minimally invasive medical devices.

\section{Introduction}

Shape memory polymers (SMPs) show promise for use as minimally invasive medical materials..$^{1-10}$ SMPs can be processed into a variety of geometries, including highly porous, ultra-low density foams. ${ }^{1,2}$ A range of SMPs have been proposed for use in medical applications, and polyurethane SMPs are of particular interest due to their excellent biocompatibility. ${ }^{3-10}$ Polyurethane SMP foams have demonstrated rapid, stable blood clot formation, superior immune response compared with polypropylene and silk, and tunable shape recovery for void filling. ${ }^{10,11}$ These foams have been proposed for use in several medical device applications, including aneurysm occlusion, peripheral occlusion, and vascular and coronary grafts. ${ }^{3-10}$ While SMP foams show significant promise, a drawback of polymer biomaterial systems is the limitations on in vivo imaging. ${ }^{5,12}$ Clinically, the most frequently used imaging

${ }^{a}$ Biomedical Device Laboratory, Dept of Biomedical Engineering, Texas A\&M University, College Station, TX, 77860,USA.E-mail: djmaitland@tamu.edu ${ }^{b}$ Laboratory for Synthetic-Biologic Interface, Dept of Chemistry, Texas A\&M University, College Station, TX, 77860, USA

$\dagger$ Electronic supplementary information (ESI) available. See DOI: 10.1039/c6ra28165f modality is X-ray angiography using fluoroscopy. ${ }^{13-17}$ Previously, we incorporated radio-opaque microparticle additives and demonstrated an enhancement in SMP foam X-ray opacity superior to that of a commercially-available endovascular occlusion device, a platinum Guglielmi detachable coil (GDC). ${ }^{12}$ While X-ray fluoroscopy is a powerful technique, it poses significant patient and technician risks due to the use of ionizing radiation. ${ }^{13-17}$ The development of medical materials that do not rely on fluoroscopy can reduce these risks. ${ }^{13-17}$

Fluorescence-guided procedures are widely used in ophthalmic examinations, such as retinal angiography. They have been shown to improve clinical outcomes and are gaining popularity in a variety of applications. ${ }^{18-22}$ Fluoresceins and near-infrared (NIR) dyes have been utilized clinically for fluorescent imaging applications, and demonstrated excellent biocompatibility and clearance by the body ${ }^{23-25}$ We investigated two imaging methods, NIR fluorescence (700-1000 nm) and visible light fluorescence, due to the transparency windows of human tissues to certain light wavelengths. Namely, the fluorescence spectra reported for aqueous phloxine $\mathrm{B}(\mathrm{PhB})$ has emission peaks between $530 \mathrm{~nm}$ and $570 \mathrm{~nm}$. Eosin Y (Eos) has emission peaks between $515 \mathrm{~nm}$ and $540 \mathrm{~nm}$. These emission tails $(600 \mathrm{~nm})$ correspond to wavelengths that have reasonable transmission through soft tissue and blood. NIR dyes, such as 
indocyanaine green (IcG, emission at $+800 \mathrm{~nm}$ ), offer another method of optically viewing SMPs in the body, as there is an optical window of minimal absorption in human tissue from approximately $700 \mathrm{~nm}$ to $900 \mathrm{~nm} \cdot{ }^{26-31}$

Inclusion of fluorescent moieties can potentially enhance additional functionalities, such as antimicrobial properties, sensing, or medical device analysis. PhB and Eos are two inexpensive fluorescein derivatives that possess reactive sites, and they are used as cosmetic and drug additives in the United States and as food additives in Japan. These dyes have been found to be antimicrobial due to the halogenation of the benzoic acid moiety and the production of singlet oxygen and reactive oxygen species with light interaction..$^{32-34}$ The use of photodynamic treatments with these molecules has been shown to reduce both antibiotic-susceptible and methicillinresistant Staphylococcus aureus (MRSA) cultures, which are of concern for device-transmitted infections. ${ }^{35-41}$ IcG has also been demonstrated as an antimicrobial dye, and has been utilized with polyurethanes as a method of reducing MRSA infection. Additionally, fluorescein molecules have been indicated for their antioxidant roles in preventing the development of reactive oxygen species predecessors.

Fluorescence has found use in polymer systems for temperature/chemical sensors and imaging particles. ${ }^{42-45}$ Despite the use of fluorescent dyes in a range of applications, they have not been widely utilized in SMPs for medical devices. In such devices, the enhanced fluorescence could allow for imaging through blood/solid tissue, as well as for self-cleaning and degradation resistance. Previous efforts to include fluorescent molecules into biomaterial systems via physical dispersion into the bulk polymer have resulted in inconsistent dye dispersion. Scaffolding techniques, such as electrospinning, have been shown to reduce dispersion issues. ${ }^{12}$ Previously, Torbati et al. reported the synthesis of fluorescent SMPs in an electrospun web by physically adding IcG to the polymer. $^{12}$ The use of high speed mixing can promote homogeneous dispersion of dye throughout polymeric materials prior to foaming without the need for additional processing steps, as has been previously shown with nanocomposites. ${ }^{46}$ Our group previously physically incorporated IcG dyes into SMPs to enable laser shape memory actuation. ${ }^{47-49}$ However, the incorporation of IcG into polyurethane foams, even when well-dispersed in the polymer, has been shown to significantly reduce mechanical properties (up to $60 \%$ reduction in elasticity)..$^{34}$

To prevent negative effects on foam properties, we have covalently incorporated in-chain fluorescent dyes into our SMP foams. The methods reported here are focused on PhB, Eos, IcG, and calcein (Cal). The covalent crosslinking of dye has also been confirmed with rhodamine and sulfarhodamine, and these methods could be applied to alternate dyes that have similar functional groups. The physical, thermal, mechanical, and optical properties of fluorescent SMP foams with and without the inclusion of additional radio-opaque microparticles are examined. Focus is placed on $\mathrm{PhB}$ due to its superior in vitro imaging performance, and IcG for potential as a remotelyactuated SMP using applied NIR light.

\section{Materials and methods}

\section{Materials}

All chemicals were purchased from Sigma Aldrich and used without modification or cleaning, unless otherwise stated. $N, N, N^{\prime}, N^{\prime}$-Tetrakis(2-hydroxypropyl)ethylenediamine (HPED, 99\%), triethanolamine (TEA, 98\%, Alfa Aesar), and 2,2,4-trimethyl hexamethylene diisocyanate (TMHDI, TCI America, a mixture of 2,2,4 and 2,4,4 monomers) were used as monomers. Ethyl isocyanate (98\%, Sigma) was used for confirming urethane syntheformation. Fluorescent monomers, shown in Fig. 1, PhB (99\%), Eos (99\%), IcG (95\%), and Cal (99\%) (ChemImpex Int'l Inc.) were identified as having functional groups that react with isocyanate groups similarly to alcohol groups, and were added without modification. All reactive monomers are shown in Fig. 1. The additives barium sulphate $\left(\mathrm{BaSO}_{4}\right.$, particle size of $3 \mu \mathrm{m}, 99 \%)$, zirconium oxide $\left(\mathrm{ZrO}_{2}\right.$, particle size of $5 \mu \mathrm{m}, 99 \%$ ), and tungsten (W, particle size $>1 \mu \mathrm{m}, 99.95 \%$, Alfa Aesar) were used without modification.

\section{Synthesis}

TEA, HPED and TMHDI were reacted to form a prepolymer mixture with an excess of isocyanates, in a process described elsewhere. ${ }^{2,42}$ The prepolymer was later reacted with residual alcohols and the fluorescent monomers during the foaming process. ${ }^{50,51}$ The fluorescent monomers were added at 1.000 , $0.500,0.050,0.010$ and $0.001 \mathrm{wt} \%$. For the composite materials, physical additives were added with the final alcohols and fluorescent monomers ( $0.050 \mathrm{wt} \%$ fluorescent monomer). Physical additives were added at 1 and $4 \mathrm{vol} \%$, as well as $10 \mathrm{vol} \%$ for $\mathrm{ZrO}_{2}$. Foams were evaluated for homogenous pores before cleaning and processing. After cleaning, foams were dried and stored with desiccant in a sealed container.

To confirm the formation of urethanes, stoichiometric amounts of dyes and ethyl isocyanates were allowed to react overnight; urethane formation was confirmed by NMR (Mercury 300, Varian Inc, Palo Alto, CA).

\section{Bulk material characterization}

Bulk foam characteristics were quantified and compared with nonfluorescent (control containing no fluorescent molecules in the polymer, no fluoro) SMP foams.

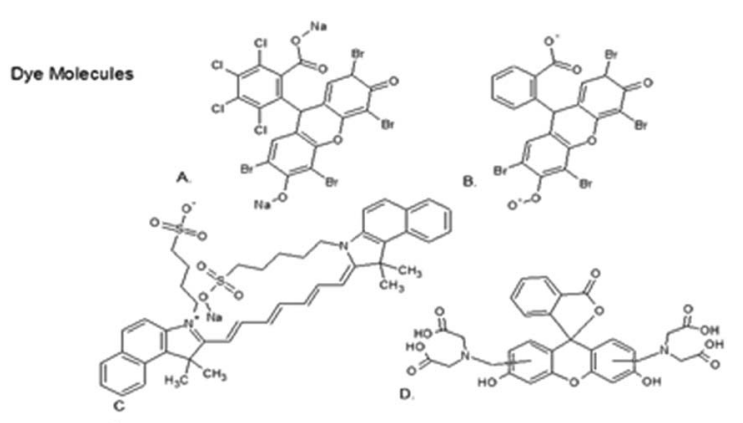

Fig. 1 The monomers dye molecule structures are shown: (A) Phloxine B (PhB), (B) Eosin Y, (C) indocyanine green (IcG), (D) calcein. 
Foam cell structure was determined by cutting axial and transverse samples that were examined using scanning electron microscopy (SEM). Samples were mounted onto a stage and sputter coated with gold using a Cressington Sputter Coater (Ted Pella, Inc., Redding, CA) for 60 seconds at $20 \mathrm{~mA}$. Samples were then examined using a Joel NeoScope JCM-5000 SEM (Nikon Instruments Inc., Melville, NY) at $11 \times$ magnification and $15 \mathrm{kV}$ under high vacuum.

Dynamic mechanical analysis (DMA) was used to conduct thermomechanical analysis using a Q800 TA DMA (TA Instruments, New Castle, DE). Five cylindrical samples (6 mm diameter, $5 \mathrm{~mm}$ length) of each concentration were examined. Dry temperature sweep samples were equilibrated at $20{ }^{\circ} \mathrm{C}$ for fifteen minutes and then ramped to $120{ }^{\circ} \mathrm{C}$ at a rate of $2{ }^{\circ} \mathrm{C}$ $\min ^{-1}$. The storage modulus $\left(\mathrm{E}^{\prime}\right)$ and the loss modulus $\left(\mathrm{E}^{\prime \prime}\right)$ were used to determine the peak tan $\delta\left(\mathrm{E}^{\prime} / \mathrm{E}^{\prime \prime}\right)$, with the maximum value recorded as the dry $T_{\mathrm{g} .}{ }^{51}$ Wet samples were examined using previously reported methods, which discusses the immersion apparatus and methodology in greater detail. ${ }^{42}$ In short, samples submerged for five minutes in $50{ }^{\circ} \mathrm{C}$ reverse osmosis (RO) water, and were then equilibrated at $25{ }^{\circ} \mathrm{C}$ followed by heating at a rate of $1{ }^{\circ} \mathrm{C} \min ^{-1}$ to $70{ }^{\circ} \mathrm{C}$. The temperature of the $\tan \delta$ maxima was recorded as the wet $T_{\mathrm{g}}{ }^{51}$ Differential scanning calorimetry (DSC) was also used to measure both wet and dry $T_{\mathrm{g}}$ using a Q-200 DSC (TA Instruments, Inc., New Castle, DE). Samples of approximately $5.0 \mathrm{mg}$ $\pm 1.0 \mathrm{mg}$ were sealed in TZero aluminium pans and placed in the heating cell. The test profile was as follows: equilibration at $-40{ }^{\circ} \mathrm{C}$, heating to $120^{\circ} \mathrm{C}$ at $10{ }^{\circ} \mathrm{C} \mathrm{min}^{-1}$, cooling $10^{\circ} \mathrm{C} \mathrm{min}^{-1}$ to $-40{ }^{\circ} \mathrm{C}$ and holding for 5 minutes, and a final heating to $120^{\circ} \mathrm{C}$ at $10{ }^{\circ} \mathrm{C} \mathrm{min}^{-1}$. The half-height transition of the final heating cycle was the reported $T_{\mathrm{g}}$. Wet samples were weighed and sealed in the same manner, and were then heated from $-40{ }^{\circ} \mathrm{C}$ to $80{ }^{\circ} \mathrm{C}$.

Thermogravimetric analysis (TGA) was performed using a TA Q50 TGA (TA Instruments, New Castle, DE). Heating at a rate of $10{ }^{\circ} \mathrm{C}$ min $^{-1}$ from $20{ }^{\circ} \mathrm{C}$ to $500{ }^{\circ} \mathrm{C}$ was performed under a mixed atmosphere with a total flow rate of $100 \mathrm{~mL} \mathrm{~min}^{-1}(60 \mathrm{~mL}$ $\min ^{-1}$ oxygen, $40 \mathrm{~mL} \mathrm{~min}^{-1}$ nitrogen). Samples were examined for degradation temperature and percentage mass lost.

Uniaxial tensile testing was performed on ASTM d638 IV samples using an Insight 30 Material Tester (MTS Systems Corp, Eden Prairie, MN). The extension rate was set to $5 \mathrm{~mm} \mathrm{~min}^{-1}$ at room temperature, and twelve samples were tested for each species. Elastic modulus, strain to failure, ultimate tensile strength, and toughness were examined for non-fluorescent foams and the highest dye-loaded samples.

\section{Shape recovery characterization}

Shape recovery of bulk foam samples crimped over a wire was examined at $50{ }^{\circ} \mathrm{C}$ in $\mathrm{RO}$ water to determine the volume recovery behavior (strain recovery). Cylindrical samples (6 $\mathrm{mm}$ diameter and $10 \mathrm{~mm}$ length, six samples per series) were crimped to a minimal diameter using a SC150-42 Stent Crimper (Machine Solutions, Flagstaff, AZ). The samples were equilibrated at $100{ }^{\circ} \mathrm{C}$ for ten minutes and then radially compressed and cooled to room temperature. After reaching room temperature, samples were allowed to relax for 12 hours before testing over the course of 30 minutes. Image $\mathrm{J}$ was used for analysis of the change in diameters over time.

To assess laser actuation profiles, SMP foams with $0.500 \%$ IcG were cut to a diameter of $\sim 6 \mathrm{~mm}$ and radially compressed over a cleaved tip optical fiber $(200 / 220 / 239 \mu \mathrm{m}$ core/cladding/ buffer) using a stent crimper. Compressed samples were immersed in a beaker of RO water at $39{ }^{\circ} \mathrm{C}$ and allowed to thermally equilibrate before testing. An $810 \mathrm{~nm}$ continuous wave $(\mathrm{CW})$ laser was fired at $3 \mathrm{~W}$ to actuate the foam. Images were taken before and during expansion.

\section{Spectroscopic analysis}

Attenuated total reflectance Fourier transform infrared spectroscopy (ATR-FTIR) spectroscopy was used to determine any spectroscopic changes to the bulk material, although no significant changes were expected. ATR-FTIR spectra were taken using a Bruker ALPHA infrared spectrometer (Bruker, Billerica, MA) using 32 scans per spectra for both background and samples. Spectra data was collected in absorption mode with a resolution of $4 \mathrm{~cm}^{-1}$. OPUS software was used to examine spectra, identify peaks, and perform baseline and atmospheric corrections. Examinations were performed in triplicate to confirm results. The obtained spectra were compared to the SMP without dye and to previously reported spectra. ${ }^{30,31}$

\section{Optical characterization}

Foams were examined both qualitatively and quantitatively. Cylindrical foam samples of $6 \mathrm{~mm}$ diameter and approximately $3 \mathrm{~cm}$ length were compressed along monofilament line and stretched in a custom frame. X-ray and fluorescence images were taken of each sample.

X-ray images were acquired on a Bruker In-Vivo Xtreme multimodal preclinical imaging system (Bruker BioSpin Corp., Billerica, MA) outfitted with a 4 MP back-thinned, backilluminated 4 MP CCD detector. ${ }^{42}$ X-rays were collected with an exposure time of $1.0 \mathrm{~s}$; f-stop $=1.40 ; \mathrm{FOV}=153.0 \mathrm{~mm}$; vertical and horizontal resolution $=377 \mathrm{ppi}$; and X-ray energy $=$ 45 KVP. Images were processed using Bruker molecular imaging software. Background was subtracted using an illumination correction reference obtained under the same conditions. To quantify the radio-opacity for each material, a length of $0.48 \mathrm{~cm}$ was selected in the X-ray image as the region of interest. 68 samples of X-ray density (X.D.) were collected within the region of interest utilizing Bruker Molecular Imaging Software. From these measurements, a mean and standard deviation of the X.D. was calculated.

Fluorescence wavelengths were examined using a Fluoromax Fluorometer (Horiba UK Limited, Middlesex, UK). Nonfluorescent foams, $0.010 \%$ samples, composite samples and particles in solution were assessed to determine emission wavelength maxima. Selected excitation wavelengths were determined from literature and confirmed by excitation scans; PhB was excited with approximately $515 \mathrm{~nm}$, Eos with $545 \mathrm{~nm}$, IcG with $795 \mathrm{~nm}$, and Cal with $490 \mathrm{~nm} .^{52}$ 

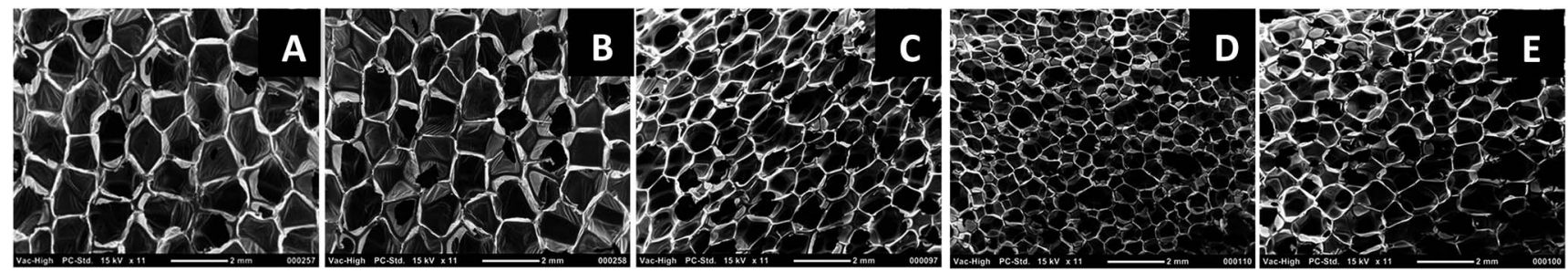

Fig. 2 SEM of SMP foams: (A) non-fluorescent control, (B) 1.0\% PhB, (C) 1.0\% Eos, (D) 1.0\% IcG, and (E) $1.0 \%$ Cal.

To quantify fluorescence, images were acquired on a Bruker In-Vivo Xtreme multimodal preclinical imaging system. Image acquisition times and conditions were optimized for each fluorophore, with collection conditions as follows: $\mathrm{PhB}=0.95 \mathrm{~s}$, $\lambda_{\mathrm{ex}}=515 \mathrm{~nm}$, and $\lambda_{\mathrm{em}}=560 \mathrm{~nm}$; Eos $=0.95 \mathrm{~s}, \lambda_{\mathrm{ex}}=520 \mathrm{~nm}$, and $\lambda_{\mathrm{em}}=600 \mathrm{~nm} ; \mathrm{IcG}=4.1 \mathrm{~s}, \lambda_{\mathrm{ex}}=730 \mathrm{~nm}$, and $\lambda_{\mathrm{em}}=830 \mathrm{~nm}$; and $\mathrm{Cal}=1.25 \mathrm{~s}, \lambda_{\mathrm{ex}}=480 \mathrm{~nm}$, and $\lambda_{\mathrm{em}}=535 \mathrm{~nm}$. For all images the $\mathrm{f}$-stop $=2.0, \mathrm{FOV}=190.0 \mathrm{~mm}$, and vertical and horizontal resolution $=273$ ppi. Images were processed using Bruker molecular imaging software. Background was subtracted using an illumination correction reference obtained under the conditions noted for each sample. To quantify the fluorescence signal, a length of $0.63 \mathrm{~cm}$ was selected along the longitudinal line of each material within the fluorescence image

A.

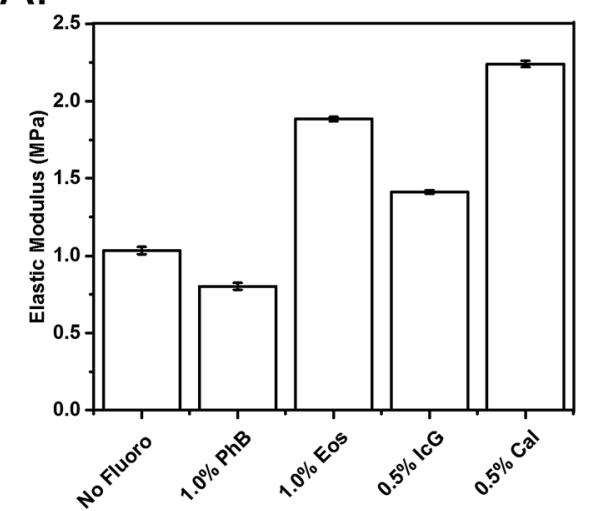

C.

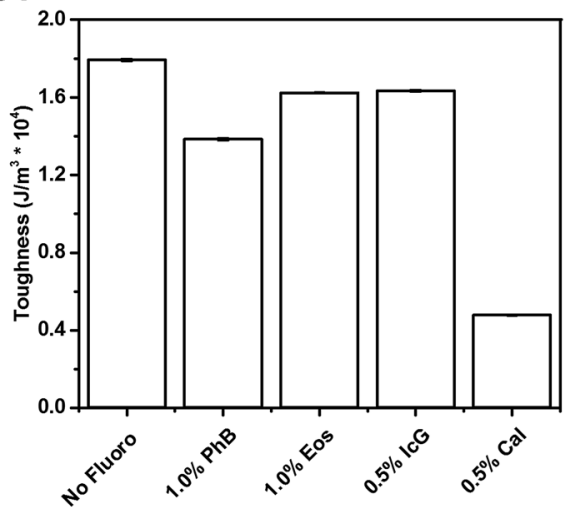

as the region of interest. Each region of interest is equal to 69 measurements of fluorescence intensity (I). From these measurements, the mean and standard deviations of fluorescence intensity were calculated.

\section{In vitro imaging}

$\mathrm{PhB}$ samples were selected for in vitro testing due to their high fluorescence, quantum yields, and NIR tail emission. PhB samples in cubic $(1 \mathrm{~cm} \times 1 \mathrm{~cm} \times 1 \mathrm{~cm})$ and radially compressed geometries were utilized for optical characterization. Porcine blood, obtained as a part of an existing tissue share program with the Rosenthal Meat Science and Technology Center at Texas A\&M University (College Station, TX), was treated with sodium citrate to prevent clotting. All blood
B.

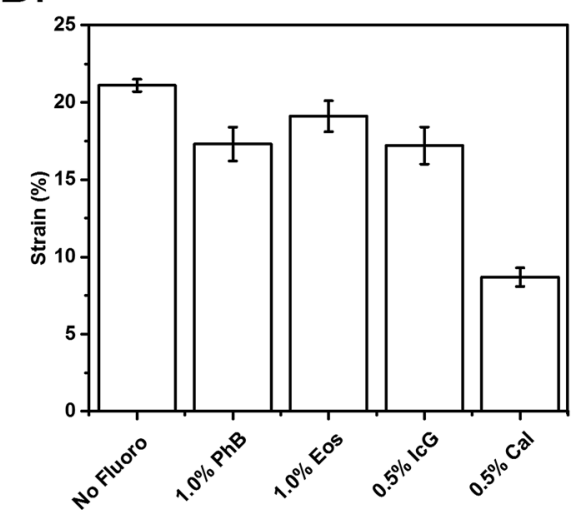

D.

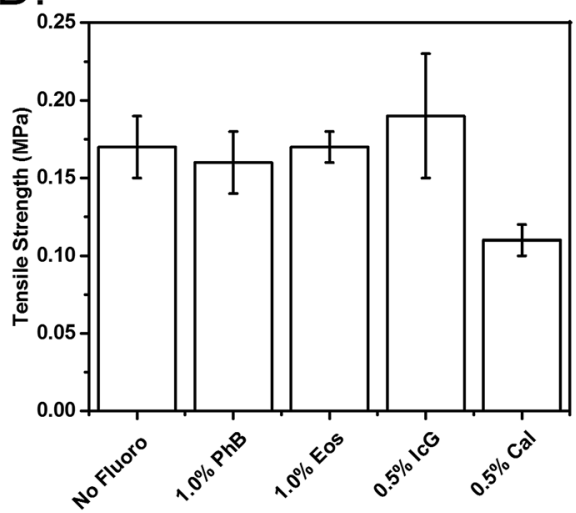

Fig. 3 Mechanical properties of fluorescent SMPs, with elastic moduli (A), strain to failure (B), toughness (C), and ultimate tensile strength (D) displayed. Mean \pm standard deviation displayed, $n=8$. 
used in this study was obtained from animals euthanized for purposes unrelated to this work. SMP samples were imaged using an Olympus Fluoview 1000 laser scanning confocal microscope (LSCM) (Olympus America Inc, Center Valley, PA), and were excited at $543 \mathrm{~nm}$ utilizing $<1 \%$ maximum intensity. A band pass filter (555 $\mathrm{nm}$ to $650 \mathrm{~nm}$ ) with a monochromator and PMT was used for signal collection. The excitation and collection objective was $10 \times$. PhB samples were placed in a Petri dish and completely submerged in blood. The excitation wavelength of $515 \mathrm{~nm}$ was passed from the bottom of the dish (approximately $0.5 \mathrm{~cm}$ path length) through the foam.

Crimped foams of $0.050 \%, 0.500 \%$ and $0.886 \% \mathrm{PhB}$ were placed in a Petri dish and excited under ambient light with a 3 $\mathrm{mW} 450 \mathrm{~nm}$ LED. They were then submerged in approximately $1 \mathrm{~cm}$ of blood, and the procedure was repeated. Qualitative observations of visible fluorescence were recorded.

Poultry tissue $(1 \mathrm{~cm}$ thickness, obtained from the local grocery store) was used to examine visualization through soft tissue. Compressed samples used in previous studies were imaged through the tissue using the same experimental parameters detailed earlier for the Bruker In-Vivo Xtreme multimodal preclinical imaging system.

\section{Results and discussion}

\section{Bulk material characterization}

SEM images of the SMPs are shown in Fig. 2, with no distinct differences between the pore morphology or membranes for the control material (no fluoro) and fluorescent SMPs foams. PhB and Eos displayed similar morphology to the control SMP. IcG and Cal-containing foams displayed decreased pore size and increased pore rupturing. Thermal analysis demonstrated no significant alterations to the $T_{\mathrm{g}}$ (approximately $90 \pm 2{ }^{\circ} \mathrm{C}$ dry $T_{\mathrm{g}}$ and $55 \pm 2{ }^{\circ} \mathrm{C}$ wet $T_{\mathrm{g}}$ by DMA; approximately $65 \pm 2{ }^{\circ} \mathrm{C}$ dry $T_{\mathrm{g}}$ and $48 \pm 1.5^{\circ} \mathrm{C}$ wet $T_{\mathrm{g}}$ by DSC). These nominal deviations in the physical characteristics demonstrate that the inclusion of the PhB and Eos dyes do not significantly alter the bulk material. While greater examination of solvent-thermal shape recovery is beyond the scope of this work, previous studies have found that the significant relaxation of the similar SMPs correlates well with decreased $T_{\mathrm{g}} \mathrm{S}$ presented here. ${ }^{42,53}$ TGA traces revealed a slight increase in degradation onset temperature for foams with dye compared to the control material. The control material had an onset degradation temperature of approximately $240{ }^{\circ} \mathrm{C}$, while the dye-containing materials had onset temperatures of approximately $255{ }^{\circ} \mathrm{C}$. A urethane peak at approximately $157 \mathrm{ppm}$, and the characteristic aliphatic urethane formation was confirmed by FTIR.

Tensile testing, Fig. 3, demonstrated that PhB SMPs are the most similar to the control in terms of tensile properties. Cal inclusion resulted in the greatest material alterations, with more than double the elastic modulus and approximately half the tensile strength, strain to failure, and toughness relative to the control. While these results indicate an effect of dye addition on SMP mechanical properties, some variations can be attributed to discrepancies in pore sizes. Pore size variation is caused both by dye additives and by minute variations in the foam synthesis.

\section{Shape recovery characterization}

It was also necessary to determine if the dye altered the foam shape recovery kinetics. Bulk expansion behavior of the fluorescent foams is shown in Fig. 4A. Recovery kinetics and volume of the PhB SMP were most similar to the control sample. Eos inclusion caused decreased time to actuation (faster recovery) and the Cal-containing SMP had reduced final volume. Despite these minor variations, all SMPs had relatively similar shape recovery behaviors.

Utilization of these materials in more rigorous in vitro scenarios as well as in vivo is necessary for confirmation of their potential for use in medical devices. No IcG-containing foam expansion was observed over the five minute equilibration time at body temperature, which was expected based on previous data as well as the wet $T_{\mathrm{g}}$ of the SMP $\left(48{ }^{\circ} \mathrm{C}\right.$ by DSC) ${ }^{42}$ Fig. $4 \mathrm{~B}$ shows the IcG foam sample threaded over a fiber optic, compressed to a minimal diameter, and expanded in a water bath using $810 \mathrm{~nm}$ laser irradiation, which opened the foam to a maximum diameter of $4 \mathrm{~mm}$. Volume recovery was much

\section{Shape Recovery Comparison of Fluorescent SMPs}
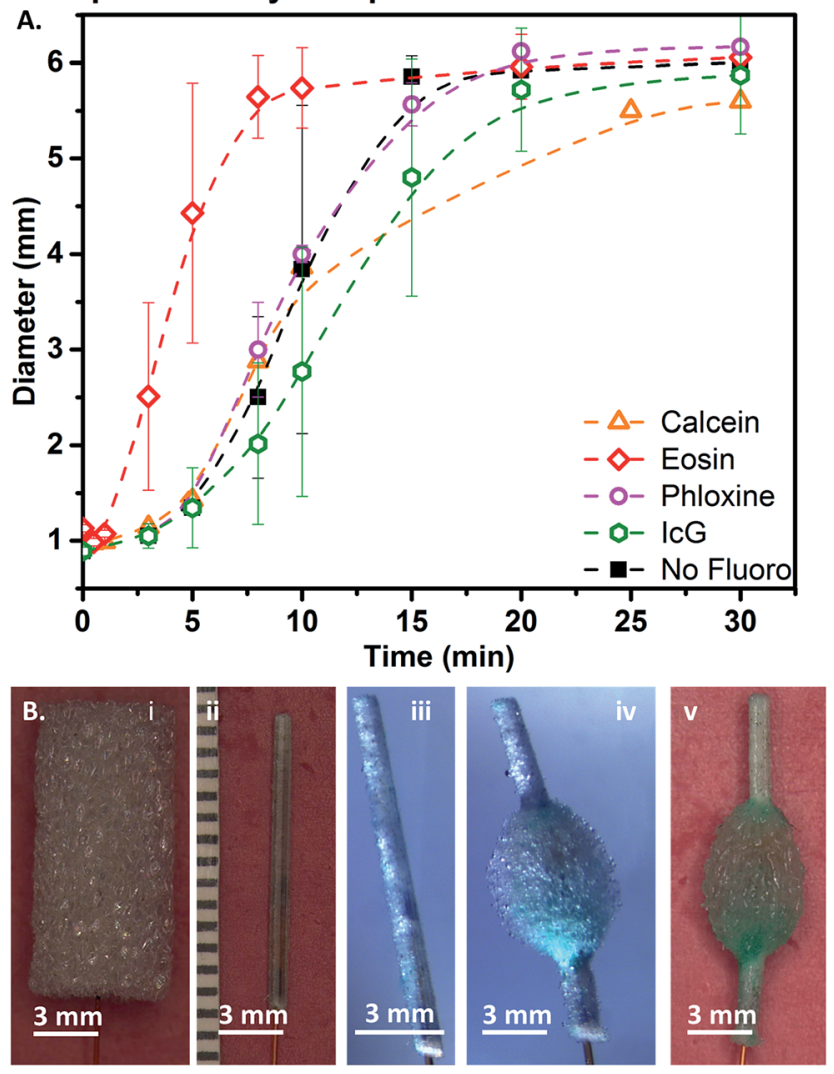

Fig. 4 (A) Shape recovery of control (no fluoro) and fluorescent SMP foams in $50{ }^{\circ} \mathrm{C}$ RO water. (B) Images of ICG foam (wet $T_{\mathrm{g}}$ of approximately $50^{\circ} \mathrm{C}$ ) laser actuation: IcG foam (i) threaded over a fiber optic, (ii) crimped to approximately $0.8 \mathrm{~mm}$, (iii) placed in a water beaker at $39{ }^{\circ} \mathrm{C}$ to equilibrate, (iv) expanded using an $810 \mathrm{~nm}$ laser in water, and (v) after removal from water. 

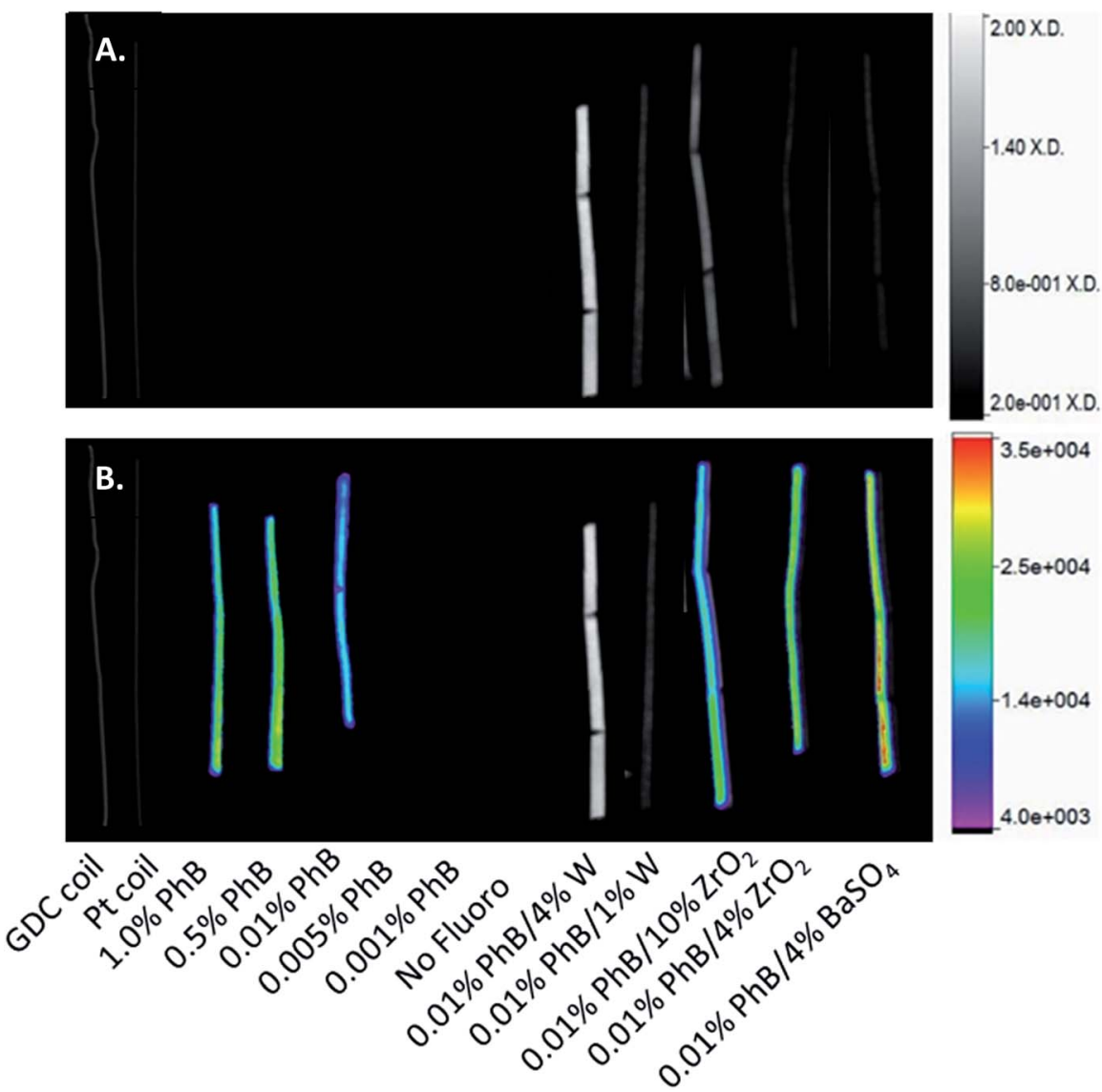

Fig. 5 Imaging analysis of PhB-containing SMPs. (A) Mean X-ray density and (B) fluorescence image overlaid with X-ray image, with fluorescence intensity denoted colormetrically (scale bar) and X-ray intensity denoted by gray scale.

lower (approximately 50\%) with laser actuation, but time to recovery was greatly increased (within seconds). Fig. $4 \mathrm{Bv}$ shows the final shape after actuation and removal from water. This experiment was repeated using PhB-containing foams using $810 \mathrm{~nm}$ laser light exposure. PhB-containing foams demonstrated laser-actuated shape recovery but with substantially lower strain recovery (approximately 20\%).

\section{Optical characterization}

The fluorescence of PhB-containing materials was examined to determine if dye crosslinking into the foam had an effect on emission or excitation wavelengths relative to those of aqueous dye solutions. A slight red shift in the dye emission wavelength was observed, which was attributed to crosslinking the dye into the polymer backbone and polarizing the fluorescent molecule. Slight variations in the emission spectra were also observed in the bulk materials relative to dye solutions, but the peak structures were not altered.

Imaging of the PhB-containing materials, shown in Fig. 5, qualitatively demonstrated that $0.5 \% \mathrm{PhB}$ loading resulted in the highest fluorescence intensity. The inclusion of $\mathrm{ZrO}_{2}$ and $\mathrm{BaSO}_{4}$ fillers increased the fluorescence emissions of PhBcontaining foams compared with the $0.01 \% \mathrm{PhB}$ foam without additives.
Quantification of fluorescence intensity showed that the standard materials, the GDC coil and Pt coil, did not possess notable fluorescence. The fluorescence intensities presented in Fig. 6 demonstrate dramatic variations in maximum achievable fluorescence intensity for each dye species. $\mathrm{PhB}$ combined with $4 \% \mathrm{BaSO}_{4}$ demonstrated the strongest emissions (30 496 units). Comparatively, $4 \% \mathrm{BaSO}_{4}$ with Eos, IcG, and Cal had emissions of 9955, 1355, and 1216 units, respectively. The 4\% $\mathrm{ZrO}_{2} \mathrm{SMP}$ composite with PhB, Eos, IcG, and Cal emitted 25 356, 11 502, 2722, and 2167 intensity units, respectively. The $\mathrm{W}$ composites had relatively low emissions with all of the tested dye additions.

\section{In vitro characterization}

Fluorescent images of PhB-containing cubes and cylinders are shown in Fig. 8. The emittance was collected between 540 and $620 \mathrm{~nm}$. The emittance on the unfilled sample in Fig. 7A is due to the intensity of the fluorescence from the $0.889 \%$ foam, not autofluorescence, as determined via imaging individual samples. The emittance a $0.5 \mathrm{~cm}$ thick sheet of foam when excited by a $540 \mathrm{~nm}$ light source is shown in Fig. 8B. The lower three loading concentrations did not emit sufficiently to be visible when compressed. Thus, Fig. 7C and F include the three highest concentration samples compressed and imaged in air and in blood, respectively. The crimped $0.05 \% \mathrm{PhB}$ device is 
A.

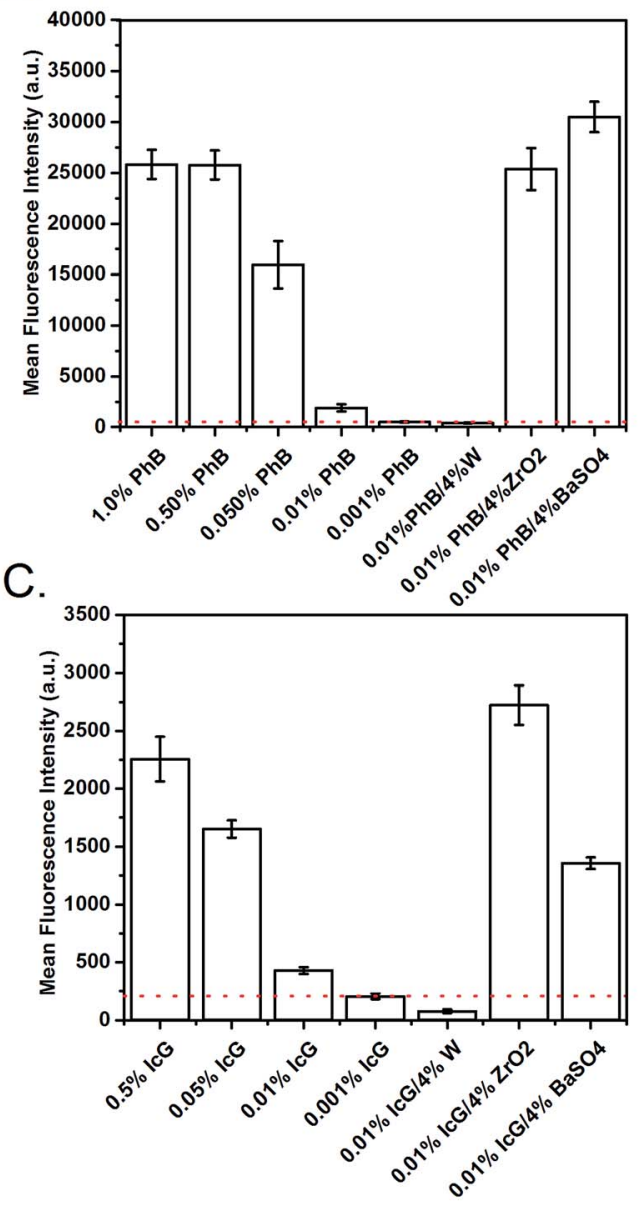

B.
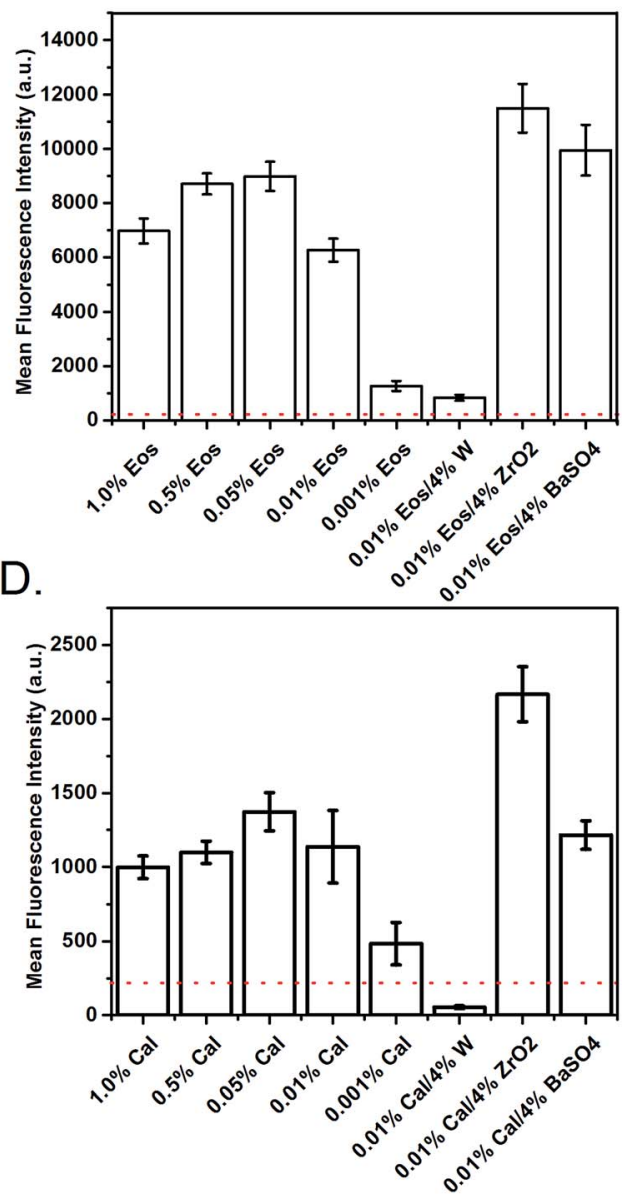

Fig. 6 Fluorescence quantification of the examined materials. Mean fluorescence intensity was measured for each species from 0.001 to $1.000 \%$ loading concentrations, and at $0.01 \%$ dye loading with $4 \%$ microparticle loadings. Negative controls (GDC coil, Pt coil, and non-fluorescent foam) are denoted by dashed line at an intensity of approximately 220 units. (A) PhB, (B) Eos, (C) IcG, and (D) Cal. Mean \pm standard deviation displayed ( $n$ $=68$.

shown submerged in approximately $1 \mathrm{~cm}$ of porcine blood, excited from beneath the blood and glass, collected using a red channel of a three color CCD camera with background subtracted. Fig. 7E shows the relative emissions of the uncompressed PhB samples (e.1: $1.0 \%$, e.2: $0.500 \%$, and e.3: $0.01 \%$ $\mathrm{PhB}$ loading) submerged in $2 \mathrm{~cm}$ of blood, with emissions collected over a $540-620 \mathrm{~nm}$ range.

The imaging of SMPs through soft tissue also indicated that the inclusion of low concentrations of $\mathrm{PhB}(0.01 \%)$ in the presence of $\mathrm{ZrO}_{2}$ or $\mathrm{BaSO}_{4}$ allows for visualization (Fig. 7G-K). As expected from the previous fluorescence examinations, the use of $\mathrm{W}$ resulted in no quantifiable fluorescence emissions, $\mathrm{ZrO}_{2}$ was more effective at lower concentrations, and $\mathrm{BaSO}_{4}$ resulted in the greatest increase in emission intensity. This may be due particles enhancing backscattering, as well as the absorbance of the excitation wavelengths ( $\mathrm{W} v s . \mathrm{ZrO}_{2}$ and $\left.\mathrm{BaSO}_{4}\right)$. It is also expected that with higher loading of $\mathrm{PhB}$ $(0.5 \%)$ would achieve similar results.

Examination of the fluorescent behavior in blood demonstrated the potential for imaging these materials in medical applications. Confocal microscopy, Fig. 8, confirmed homogenous emission from the foam struts, which could be distinctly visualized through blood. The emission spectra using a $515 \mathrm{~nm}$ excitation light source is given in Fig. 8A, and the foam strut from where it was obtained is shown in Fig. 8B. The struts appear to have uniform fluorescence, with no dark or saturated sections.

Emission peak shifts of dye-containing SMPs compared with dye solutions were as expected due to the additional stress on the dye molecules after crosslinking into the polymer compared.$^{54}$ This phenomenon also explains the variations seen in the fluorescence intensities when comparing dye-containing composite and standard materials. In general, the radiopaque additives $\mathrm{ZrO}_{2}$ and $\mathrm{BaSO}_{4}$ enhanced fluorescence (Fig. 6), which could be due in part to particle size, dispersion throughout the materials, and their ability to absorb/reflect light. W, as a darker material, would absorb light rather than reflecting it, preventing the visualization enhancement that occurred with $\mathrm{ZrO}_{2}$ and $\mathrm{BaSO}_{4}$. Additionally, the mid-concentration peak fluorescence of Eos and Cal foams indicate a dye self-quenching mechanism 

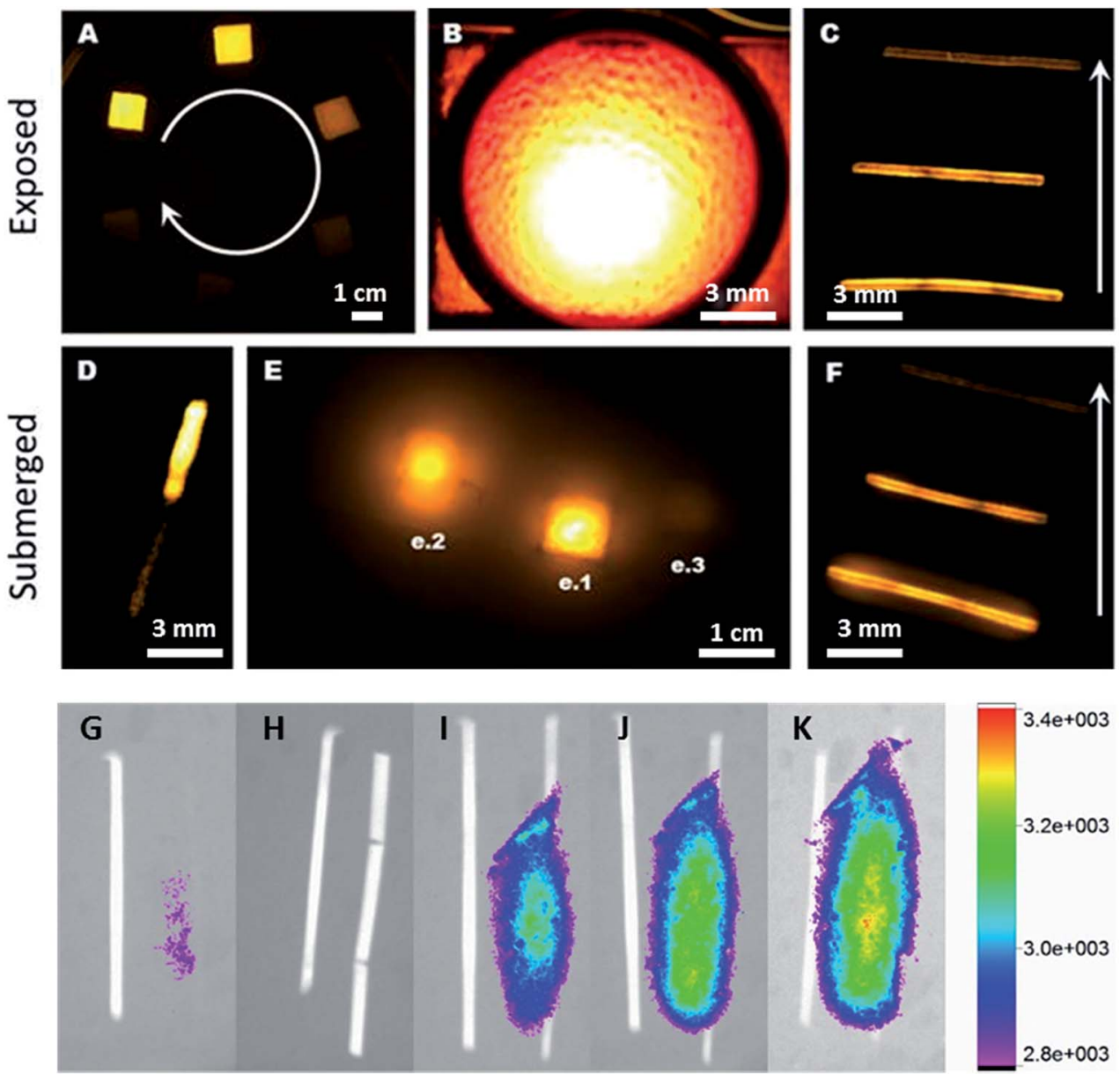

Fig. 7 Foam fluorescence of exposed (air) and submerged (blood) PhB-doped foams (A-F) and through tissue (G-K). (A) $1 \mathrm{~cm}^{3} \mathrm{cubes}$ with 1.000-0.000\% PhB (clockwise) with $485 \mathrm{~nm}$ excitation and 540 to $620 \mathrm{~nm}$ collection; (B) $2 \mathrm{~mm}$-thick $0.010 \%$ PhB foam imaged with 540 excitation through a $560 \mathrm{~nm}$ longpass filter; (C) crimped SMPs from 1.0\% (e.1), 0.5\% (e.2) and 0.01\% (e.3) PhB (bottom to top) with $485 \mathrm{~nm}$ excitation and 540 to $620 \mathrm{~nm}$ collection; (D) crimped 1.0\% PhB device under approximately $1 \mathrm{~cm}$ of blood excited under ambient light with a 3 $\mathrm{mW} 450 \mathrm{~nm}$ LED and collected as the red channel of a three color CCD camera (background subtracted); (E) emission of $1 \mathrm{~cm}{ }^{3} \mathrm{cubes}$ of $1.0 \%$ (e.1), $0.5 \%$ (e.2) and $0.01 \%$ (e.3) PhB foams submerged under approximately $2 \mathrm{~cm}$ of blood with $485 \mathrm{~nm}$ excitation and $540-620 \mathrm{~nm}$ collection; (F) emission of crimped SMPs with 1.0\%, $0.5 \%$, and $0.01 \% \mathrm{PhB}$ (bottom to top) under approximately $1 \mathrm{~cm}$ of blood with $485 \mathrm{~nm}$ excitation and $540-$ 620 collection. $\mathrm{PhB}(0.1 \%)$ and composite SMPs with $\mathrm{PhB}(0.1 \%)$ were imaged through soft tissue, with the image overlayed with the fluorescence emission denoted colormetrically to examine intensity. SMP control and PhB-SMP are compared (G) to $4 \%$ W and $4 \%$ W with PhB (H), which displayed minimal fluorescence. The use of $10 \% \mathrm{ZrO}_{2}(\mathrm{I}), 4 \% \mathrm{ZrO}_{2}(\mathrm{~J})$ and $4 \% \mathrm{BaSO}_{4}(\mathrm{~K})$ is also presented, with the broad emission patterns attributed to the experimental design, which did not prevent backscattering (no tissue laid over the SMPs).

with increased concentrations, Fig. $6 \mathrm{C}$ and D. ${ }^{36}$ In vitro testing confirms that inclusion of $\mathrm{PhB}$ in the foams does not alter its fluorescent emissions in atmosphere or when submerged in blood. Visualization could potentially be improved by the lack of backscattering during implantation, which would contribute to a decreased signal. This method could be useful for imaging and recording tissue ingrowth into the material over time. The in vitro data demonstrates ease of visualization for both compressed and expanded materials, which broadens the utility for such applications; radio-density analysis of tissue growth in similar porous structures would only be possible in very dense, compressed materials that have not undergone shape recovery to the expanded shape. Further work is required to confirm this hypothesis, with additional confirmation required for the use of other dyes through blood and soft tissue.
Laser-actuated SMP materials possess favorable properties for intravascular medical device applications and minimallyinvasive procedures. As shown by the expansion experiments and in vitro tests, these materials do not expand on a clinicallyrelevant timescale when submerged in water at body temperature. Thus, an external, or active, actuation mechanism is required. ${ }^{55,56}$ In this application, these materials are actuated as a result of heating a dopant (dye) via laser absorption. This method offers advantages over passively actuated SMPs that actuate at body temperature, as the polymer will not recover to its original shape without active stimulation within the body. The material can be placed into a desired location without limitations on procedure time or risk of premature device expansion. In the examined method, no diffuser was used for the laser light, and thus the proximal and distal ends did not 

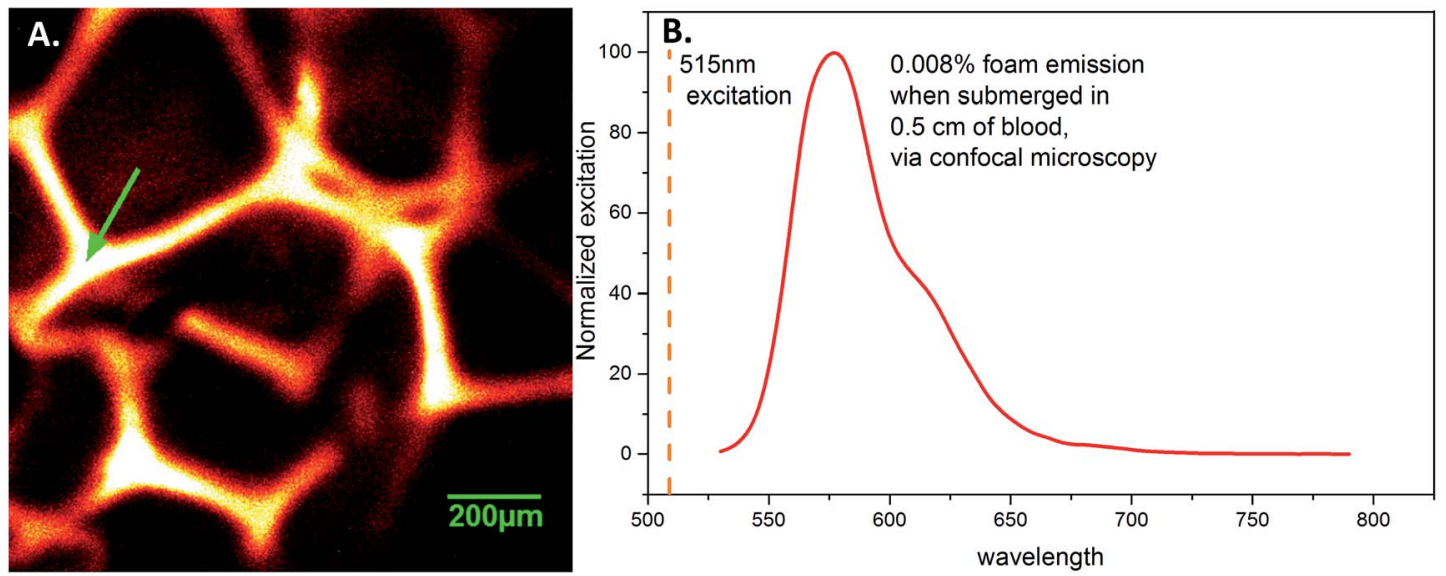

Fig. 8 (A) $0.01 \% \mathrm{PhB}$ foam struts, taken by confocal microscopy through $0.5 \mathrm{~cm}$ of porcine blood. (B) Emission spectra taken at the arrow in $\mathrm{A}$, using $515 \mathrm{~nm}$ light for excitation.

recover. By including a method of diffusing the stimuli throughout the SMP, rather than localizing it to the end of the fiber-optic, we hypothesize that recoverable volume would increase for the entire SMP.

Previously, we examined the use of physical additives in SMP foams, demonstrating the enhancement of radio-opacity through microparticle additives that did not significantly alter thermomechanical properties. ${ }^{42}$ We show here that this functionality can be simultaneously exploited along with fluorescence or NIR emissions as an additional mode of imaging materials. While $\geq 50 \%$ attenuation can occur over $5+\mathrm{cm}$ of tissue, use of NIR light in the human head has indicated that light is still detectable through hard tissue, such as bone, and other soft tissues, including cerebrospinal fluid, cerebral cortex, and skin. ${ }^{57}$ Optimization of the IcG inclusion in the material could allow for imaging through hard tissue, with IcG concentration and SMP crimping playing a large role in the emission intensity and wavelengths. ${ }^{22}$ Moving forward, we believe that these materials can be utilized as SMPs with fluorescent imaging and a potential anti-microbial functionality. Additionally, these materials could be utilized to promote biomaterial stability, as fluorescein molecules have been indicated for their antioxidant roles in preventing the development of reactive oxygen species predecessors. ${ }^{33}$ These materials also have potential as an alternative method of analyzing medical polymers via fluorescent microscopy, as well as for chemical sensors or for monitoring degradation. ${ }^{58}$ Future studies will examine the anti-microbial and degradation properties of these fluorescent SMPs. Additionally, this controlled behaviour could be useful for incorporating drug release capabilities, as demonstrated in similar studies using photothermal release from outside of the tissue, or for sensing changes in the in vivo environment. ${ }^{59-61}$

\section{Conclusions}

This study shows that the inclusion of fluorescent and NIR dyes into SMP polyurethane foams does not significantly alter the thermomechanical, shape memory, or mechanical properties (with the exception of Cal producing a more brittle material). Covalent crosslinking of dye was demonstrated with PhB, IcG, Eos, and Cal, and is possible for rhodamine and sulfarhodamine as well. PhB and IcG showed the most potential as modifiers for SMPs. These materials show promise as medical materials, as they can be synthesized to include multiple optical modalities using physical additives and low dye concentrations. The in vitro testing of these materials provides an initial indication of their promise for optical visualization through soft tissue without the utilization of harmful X-rays or radiation methods. This work offers an alternative means of implanting and/or viewing implanted devices and materials.

\section{Acknowledgements}

This work was supported by the National Institutes of Health/ National Institute of Neurological Disorders and Stroke Grant U01-NS089692, the National Heart Lung and Blood Institute Program of Excellence in Nanotechnology (HHSN268201000046C), the NASA Harriett G. Jenkins Fellowship (NNX15AU29H, A. C. W.) and the National Science Foundation (CHE-1410272). Special thanks to Anthony Boyle for his assistance with volume expansion and editing of the manuscript, and Sayyeda M. Hasan for foaming advice. We would like to acknowledge access to instrumentation within the Laboratory for Synthetic-Biologic Interactions.

\section{References}

1 P. Singhal, W. Small, E. Cosgriff-Hernandez, D. J. Maitland and T. Wilson, Low density biodegradable shape memory polyurethane foams for embolic biomedical applications, Acta Biomater., 2014, 10, 67-76.

2 P. Singhal, A. Boyle, M. L. Brooks, S. Infanger, S. Letts, W. Small, D. J. Maitland and T. S. Wilson, Controlling the actuation rate of low-density shape-memory polymer foams in water, Macromol. Chem. Phys., 2013, 214(11), 1204-1214. 
3 A. Metcalfe, A. C. Desfaits, I. Salazkin, L. Yahia, W. M. Sokolowski and J. Raymond, Cold hibernated elastic memory foams for endvascular interventions, Biomaterials, 2003, 24(9), 1681.

4 L. Sun, W. M. Huang, C. C. Wang, Z. Ding, Y. Zhao, C. Tang and X. Y. Gao, Polymeric shape memory materials and actuators, Liq. Cryst., 2014, 41(3), 277-289.

5 P. T. Matjer, X. Luo and I. A. Rousseau, Annu. Rev. Mater. Res., 2009, 39, 445-471.

6 C. M. Yakacki, S. Willis, C. Luders and K. Gall, Deformation limits in shape-memory polymers, Adv. Eng. Mater., 2008, 10(1), 112.

7 C. M. Yakacki, R. Shandas, D. Safranski, A. M. Ortega, K. Sassaman and K. Gall, Strong, tailored, biocompatible shape-memory polymer networks, Adv. Funct. Mater., 2008, 18(16), 2428.

8 C. M. Yakacki, R. Shandas, C. Lanning, B. Rech, A. Eckstein and K. Gall, Unconstrained recovery characterization of shape-memory polymer networks for cardiovascular applications, Biomaterials, 2007, 28(14), 2255.

9 T. S. Wilson, J. P. Bearinger, J. L. Herberg, J. E. Marion III, W. J. Wright, C. L. Evans and D. J. Maitland, Shape memory polymers based on uniform aliphatic urethane networks, J. Appl. Polym. Sci., 2007, 106, 540-551.

10 A. J. Boyle, T. L. Landsman, M. A. Wierzicki, L. D. Nash, W. Hwang, M. W. Miller, E. Tuzun, S. M. Hasan and D. J. Maitland, In vitro and in vivo evaluation of a shape memory polymer foam-over-wire embolization device delivered in saccular aneurysm models, J. Biomed. Mater. Res., Part B, 2015, 1407-1415.

11 J. N. Rodriguez, F. J. Clubb, T. S. Wilson, M. W. Miller, T. W. Fossum, J. Hartman, E. Tuzun, P. Singhal and D. J. Maitland, In vivo response to an implanted shape memory polyurethane foam in a porcine aneurysm model, J. Biomed. Mater. Res., Part A, 2014, 102(5), 1231-1242.

12 A. H. Torbati, R. T. Mather, J. E. Reeder and P. T. Mather, Fabrication of a light-emitting shape memory polymeric web containing indocyanine web, J. Biomed. Mater. Res., Part B, 2014, 102, 1236-1243.

13 R. J. Lederman, Cardiovascular interventional MRI, Circulation, 2005, 112(19), 3009-3017.

14 T. Rogers and R. J. Lederman, Interventional CMR: clinical applications and future directions, Curr. Cardiol. Rep., 2015, $17(31), 31$.

15 S. G. Silverman, K. Tuncali, D. F. Adams, R. D. Nawfel, K. H. Zou and P. F. Judy, CT fluoroscopy-guided abdominal interventions: techniques, results and radiation exposure, J. Vasc. Interv. Radiol., 1999, 212(3), 6.

16 C. T. Mehlman and T. G. DiPasquale, Radiation exposure to the orthopaedic surgical team during fluoroscopy: "how far away is far enough?”, J. Orthop. Trauma, 1997, 11(6), 392398.

17 C. E. Hoffler and A. M. Ilyas, Fluoroscopic radiation exposure, J. Bone Jt. Surg., 2015, 97(9), 721-725.

18 R. F. Spaide, J. M. Klancnik and M. J. Cooney, Retinal vascular layers imaged by fluorescein angiography and optical coherence tomography angiography, JAMA Ophthalmol., 2015, 133(1), 45-50.

19 G. Zilidis, F. Aziz, S. Telara and M. S. Eljamel, Fluorescence image-guided surgery and repetitive photodynamic therapy in brain metastatic malignant melanoma, Photodiagn. Photodyn. Ther., 2008, 5(4), 264-266.

20 J. Shinoda, H. Yano, S. Yoshimura, A. Okumura, Y. Kaku, T. Iwama and N. Sakai, Fluorescence-guided resection of glioblastoma multiforme by using high-dose fluorescein sodium. Technical note, J. Neurosurg., 2003, 99(3), 597-603.

21 C. A. Metildi, S. Kaushal, C. R. Hardamon, C. S. Snyder, M. Pu, K. S. Messer, M. A. Talamini, R. M. Hoffman and M. Bouvet, Fluorescence-guided surgery allows for more complete resection of pancreatic cancer, resulting in longer disease-free survival compared with standard surgery in orthotopic mouse models, J. Am. Coll. Surg., 2012, 215(1), 126-135.

22 O. R. Brouwer, T. Buckle, A. Bunschoten, J. Kuil, A. L. Vahrmeijer, T. Wendler, R. A. Valdes-Olmos, H. G. van der Poel and F. W. van Leeuwen, Image navigation as a means to expand the boundaries of fluorescence-guided surgery, Phys. Med. Biol., 2012, 57(10), 3123-3136.

23 C. Giraudeau, A. Moussaron, A. Stallivieri, S. Mordon and C. Frochot, Indocyanine green: photosensitizer or chromophore? Still a debate, Curr. Med. Chem., 2013, 17, 1871-1897.

24 R. W. Flower and B. F. Hochheimer, Indocyanine green dye fluorescence and infrared absorption choroidal angiography performed simultaneously with fluorescein angiography, Johns Hopkins Med. J., 1976, 138(2), 33-42.

25 Y. Kameda, T. Babazono, K. Haruyama, Y. Iwamoto and S. Kitano, Renal function following fluorescein angiography in diabetic patients with chronic kidney disease, Diabetes Care, 2009, 32(3), e31.

26 H. Tsuchiya, M. Sato, T. Miyazaki, S. Fujiwara, S. Tanigaki, M. Ohyama, T. Tanaka and M. Iinuma, Comparative study on the antibacterial activity of phytochemical flavanones against methicillin-resistant Staphylococcus aureus, J. Ethnopharmacol., 1996, 50(1), 27-34.

27 H. Qi, M. Kawagishi, M. Yoshimoto, H. Takano, B. Zhu, Y. Shimoishi, M. Tada, Y. Murata and Y. Nakamura, Artificial food colorants inhibits superoxide production in differentiated HL-60 cells, Biosci., Biotechnol., Biochem., 2010, 74(8), 1725-1728.

28 D\&C Red No. 27 [CASRN 13473-26-2]. NIH MSDS, 2000, http://ntp.niehs.nih.gov/ntp/htdocs/chem_background/ exsumpdf/reddyes_508.pdf.

29 Y. Pu, W. B. Wang, G. C. Tang, F. Zeng, S. Achilefu, J. H. Vitenson, I. Sawczuk, S. Peters, J. M. Lombardo and R. R. Alfano, Spectral polarization imaging of human prostate cancer tissue using a near-infrared receptortargeted contrast agent, Technol. Cancer Res. Treat., 2005, 4(4), 429-436.

30 E. I. Altinoglu and J. H. Adair, Near infrared imaging with nanoparticles, Wiley Interdiscip. Rev.: Nanomed. Nanobiotechnol., 2010, 2(5), 461-477. 
31 J. V. Frangioni, In vivo near-infrared fluorescence imaging, Curr. Opin. Chem. Biol., 2003, 7(5), 6262-6634.

32 S. Noimark, C. W. Dunnill and I. P. Parkin, Shining light on materials - a self-sterilising revolution, Adv. Drug Delivery Rev., 2013, 65(4), 570-580.

33 H. Qi, M. Kawagishi, M. Yoshimoto, H. Takano, B. Zhu, Y. Shimoishi, M. Tada, Y. Murata and Y. Nakamura, Artificial food colorants inhibits superoxide production in differentiated HL-60 cells, Biosci., Biotechnol., Biochem., 2010, 74(8), 1725-1728.

34 S. Perni, J. Pratten, M. Wilson, C. Piccirillo, I. P. Parkin and P. Prokopovich, Antimicrobial properties of light-activated polyurethane containing indocyanine green, J. Biomater. Appl., 2011, 25(5), 387-400.

35 A. Di Poto, M. S. Sbarra, G. Provenza, L. Visai and P. Speziale, The effect of photodynamic treatment combined with antibiotic action of host defence mechanisms on Staphylococcus aureus biofilms, Biomaterials, 2009, 30(18), 3158-3166.

36 R. Rasooly, Expanding the bactericidal action of the food color additive phloxine B to gram-negative bacteria, FEMS Immunol. Med. Microbiol., 2005, 45(2), 239-244.

37 R. Rasooly, Phloxine B, a versatile bacterial stain, FEMS Immunol. Med. Microbiol., 2006, 49(2), 261-265.

38 A. Rasooly and A. Weisz, In vitro antibacterial activities of phloxine B and other halogenated fluoresceins against methicillin-resistant Staphylococcus aureus, Antimicrob. Agents Chemother., 2002, 46(11), 3650-3653.

39 R. G. Corey, Staphylococcus aureus blood stream infections: definitions and treatment, Clin. Infect. Dis., 2009, 48, S254S259.

40 S. E. Cosgrove, G. Sakoulas, E. N. Perencevich, M. J. Schwaber, A. W. Karchmer and Y. Carmeli, Comparison of mortality associated with methicillinresistant and methicillin-susceptible Staphylococcus aureus bacteremia: a meta-analysis, Clin. Infect. Dis., 2003, 36(1), 53-59.

41 H. Tsuchiya, M. Sato, T. Miyazaki, S. Fujiwara, S. Tanigaki, M. Ohyama, T. Tanaka and M. Iinuma, Comparative study on the antibacterial activity of phytochemical flavanones against methicillin-resistant Staphylococcus aureus, J. Ethnopharmacol., 1996, 50(1), 27-34.

42 A. C. Weems, J. E. Raymond, K. T. Whacker, T. P. Gustafson, B. K. Keller, K. L. Wooley and D. J. Maitland, Examination of radio-opacity enhancing additives in shape memory polyurethane foam, J. Appl. Polym. Sci., 2015, 132(23), 42054.

43 C. Wu, H. Peng, Y. Jiang and J. McNeill, Energy transfer mediated fluorescence from blended conjugated polymer nanoparticles, J. Phys. Chem. B, 2006, 110(29), 14148-14154.

44 J. Kunzelman, T. Chung, P. T. Mather and C. Weder, Shape memory polymers with built-in threshold temperature sensors, J. Mater. Chem., 2008, 18, 1082-1086.

45 S. Perni, P. Prokopovish, I. P. Parkin, M. Wilson and J. Pratten, Prevention of biofilm accumulation on a lightactivated antimicrobial catheter material, J. Mater. Chem., 2010, 20, 8668-8673.
46 X. Han, C. Zeng, L. J. Lee, K. W. Koelling and D. L. Tomasko, Extrusion of polystyrene nanocomposite foams with supercritical $\mathrm{CO}_{2}$, Polym. Mater.: Sci. Eng., 2003, 43(6), 1261-1275.

47 W. Small, P. Singhal, T. S. Wilson and D. J. Maitland, Biomedical applications of thermally activated shape memory polymers, J. Mater. Chem., 2010, 20, 3356-3366.

48 G. M. Baer, W. Small, T. S. Wilson, W. J. Benett, D. L. Matthews, J. Hartman and D. J. Maitland, Fabrication and in vitro deployment of a laser-activated shape memory polymer vascular stent, Biomed. Eng. Online, 2007, 6, 43.

49 W. Small, M. F. Metzger, T. S. Wilson and D. J. Maitland, Laser-activated shape memory polymer microactuator for thrombus removal following ischemic stroke: preliminary in vitro analysis, IEEE J. Sel. Top. Quantum Electron., 2005, 11(4), 892.

50 D. I. Zeugolis and M. Raghunath, The physiological relevance of wet versus dry differential scanning calorimetry for biomaterial evaluation: a technical note, Polym. Int., 2012, 59, 1403-1407.

51 M. Zappa, Influence of Absorbed Moisture on the Mechanical Properties of Polyamide 6, Mettler Toledo, 2006, vol. 2, pp. 1-5.

52 Chroma Technology Corp. (n.d.), Specta Viewer | Chroma Technology Corp, Retrieved April 6, 2015, from http:// www.chroma.com/spectra-viewer?fluorochromes=10379\#tabsspectra_viewer_plot-left2.

53 A. J. Boyle, A. C. Weems, S. M. Hasan, L. D. Nash, M. B. B. Monroe and D. J. Maitland, Solvent stimulated actuation of polyurethane-based shape memory polymer foams using dimethyl sulfoxide and ethanol, Smart Mater. Struct., 2016, 25(7), 075014.

54 K. Aslan, I. Gryczynski, J. Malicka, E. Matveeva, J. R. Lakowicz and C. D. Geddes, Metal-enhanced fluorescence: an emerging tool in biotechnology, Curr. Opin. Biotechnol., 2005, 16(1), 55-62.

55 H. Lu, C. Lu, W. M. Huang and J. Leng, Quantitative separation of the influence of copper(II) chloride mass migration on the chemo-responsive shape memory effect in polyurethane shape memory polymer, Smart Mater. Struct., 2016, 25(10), 105003.

56 H. Lu, W. M. Huang, Y. Q. Fu and J. Leng, Quantitative separation of the influence of hydrogen bonding of ethanol/water mixture on the shape recovery behavior of polyurethane shape memory polymer, Smart Mater. Struct., 2014, 23(12), 125041.

57 A. E. R. Young, T. J. Germon, N. J. Barnett, A. R. Manara and R. J. Nelson, Behaviour of near-infrared light in the adult human head: implications for clinical near-infrared spectroscopy, Br. J. Anaesth., 2000, 84(1), 38-42.

58 W. I. S. Galpothdeniya, S. Da, S. L. De Rooy, B. P. Regmi, S. Hamdan and I. M. Warner, Fluorescein-based ionic liquid sensor for label-free detection of serum albumins, RSC Adv., 2014, 4, 17533.

59 Z. Meng, X. Chen, Z. Liu, S. Chen, N. Yu, P. Wei, Z. Chen and M. Zhu, NIR-laser-triggered smart full-polymer nanogels for 
synergic photothermal-/chemo-therapy of tumors, $R S C A d v$., 2016, 6, 90111.

60 R. Jenkins, M. K. Burdette and S. H. Foulger, Mini-review: fluorescence imaging in cancer cells using dye-doped nanoparticles, $R S C A d v$., 2016, 6, 65459.
61 S. Mohandoss, J. Sivakamavalli, B. Vaseeharan and T. Stalin, Fluorometric sensing of $\mathrm{Pb}^{2+}$ and $\mathrm{CrO}^{42-}$ ions through hostguest inclusion for human lung cancer live cell imaging, $R S C$ $A d v .$, 2015, 5, 101802. 